\title{
Development and Behavior of Mechanical, Chemical resistance and Morphology Properties of Silicon / Coir Fiber Reinforced Epoxy Hybrid Composites
}

\author{
A. Shirish Kumar ${ }^{1}$, V. Nikil Murthy ${ }^{2, *}$, C.B.N Murthy ${ }^{3}$ \\ ${ }^{1} \mathrm{M}$ Tech, Machine Design, Mechanical Engineering Department, Geethanjali College of \\ Engineering and Technology, Cheeryal(v),Keesara(m),Ranga Reddy Dist, Telangana, India. \\ ${ }^{2}$ Department of Mechanical Engineering, M.V.S.R. Engineering College, Nadergul, Hyderabad- \\ 515401, Telangana, India. \\ ${ }^{3}$ Department of Mechanical Engineering, Geethanjali College of Engineering and Technology, \\ Cheeryal(v),Keesara(m),Ranga Reddy Dist, Telangana, India. \\ * Corresponding Author: murthy362@gmail.com
}

Keywords: Coir Fiber, Epoxy, Flexural Test, Tensile Test, Tensile Modulus and Morphology.

\begin{abstract}
Room temperature cured epoxy was impregnated with coir fiber in order to synthesis composites. Coir fiber is taken in the $3 \& 5 \%$ weight in order to suspend on epoxy resin. Two different proportions of Silicon / Coir fiber hybrid composites were prepared by incorporated into the Epoxy as the core material using rule of hybrid mixtures (RoHM). Mechanical properties like flexural strength and modulus, tensile strength and modulus and morphological properties were also studied. Composites were prepared using hand layup technique in presence of hot compression molding technique. The mechanical properties of Silicon / Coir fiber hybrid composites were investigated with reference to the relative weight of Silicon and Coir fiber. The chemical resistance of hybrid composites with and without alkali treatments has been studied. Variation of a fore mentioned mechanical properties and chemical resistance has been studied with different combinations of Silicon and coir fiber as reinforced into epoxy matrix. Fiber, filler reinforced plastics have replaced the metals in Aerospace, Marine, Chemical and Transport industries. Fiber, filler reinforced plastic have gained recognition as structural material. The most important reason for replacing composite materials is that, substantial weight saving can be achieved and strength to weight, and stiffness to weight ratios are superior to the conventional materials of aircraft structures such as aluminum alloy. Composites are materials based on the controlled distribution of one or more materials, termed as reinforcement, in a continuous phase of second materials, called the matrix. The reinforcement is added to provide strength and stiffness to a composite. The matrix is also known as 'Binder' material.
\end{abstract}

\section{INTRODUCTION}

Higher motional exactness and dimensional stability are the important advantages of smaller devices; highly precise measurements or movements are possible on small scale. Finally smaller things need less energy in order to function. Power consumptions can make or break a new product design, and miniaturization is one way to minimize the fuel factor. Power density is the amount of power that can be generated per unit volume, also favors miniaturization. With the growth in environmental awareness and advancement of civilization, man is looking for new materials, which emerge out from advanced technology to meet livelihood requirements. So, to meet ever-growing and specified performance requirements, professionals started fabricating novel materials from renewable sources or manipulation of the existing old materials. Present conventional materials may not fulfill all the performance requirements.

During the past 10 years, a lot of fundamental and applied research has been carried out in polymer matrix composites. Due to the molecular size and their reinforcement, polymer composites offer ample possibility to develop new material with usual properties. Thermoset polymers have 
been widely used for engineering components, adhesives and matrix for fiber reinforced composites due to their good mechanical properties compared to those of thermoplastic polymers. However, since they are usually brittle and vulnerable to crack, ductile thermoplastic materials such as microsized rubber or nylon particles are added to the polymer to increase their fracture toughness, which compromises the strength of thermoset polymers. The addition of rigid microsized fillers to polymer, often increase its strength, but decreases the toughness since the filler of agglomerates may induce stress concentration, which initiates crack and make them become larger than the critical crack size eventually causes the failure. Therefore it is a good way to reinforce the polymer with particles in order to increase the fracture toughness without sacrificing the mechanical strength of the polymers because well dispersed nanoparticles are much smaller than the crack size to initiate failure. Thus composites provide avenue for simultaneously toughening and strengthening of the polymers.

One of the most important focuses in achieving this goal is to develop a new material, which possesses a strength-to-weight ratio that far exceeds any of the present materials. Epoxy resin remains the most important matrix used in the high-performance transportation systems. When epoxy combines with glass fibers, it results in advanced composites, which have sound-specific properties such as impact, hardness, tensile, strength, and modulus and properties. The new found properties make this material very attractive for use in aerospace applications. Estimation has it that for every unit of weight reproduction in an aircraft, there is a considerably less consumption of fuel or higher load capacity, and hence materials offer load saving. Due to their resistance to chemicals, the permeability of water, oxygen, and other gases to composites also decreases, making them ideal for building advanced composite fuel tanks for future reusable launch vehicles.

Epoxy resins which play a vital role in polymer matrix materials because of their superior mechanical and adhesive properties. They have been used widely as a matrix to hold the highperformance fiber reinforcement together in composite materials, as well as structural adhesives.

\section{Aim and Scope of the Present Work}

In the current work, two different proportions of Silicon / Coir fiber hybrid composites were prepared by dispersing into the thermoset polymer Epoxy as the resin using rule of hybrid mixtures (RoHM). Mechanical properties like flexural strength and modulus, tensile strength and modulus, chemical resistance and morphological properties were also studied. Composites were prepared by using hand layup technique in presence of hot compression molding technique. The mechanical properties of Silicon / Coir fiber hybrid composites were investigated with reference to the relative weight of Silicon and Coir fiber. The chemical resistance of hybrid composites with and without alkali treatments has been studied. Variation of a fore mentioned mechanical properties and chemical resistance has been studied with different combinations of Silicon and coir fiber as reinforced into epoxy matrix.

\section{EXPERIMENTAL DETAILS}

\section{Materials and Methods}

In the present work, epoxy resin (LY-556) is the most common thermosetting polymer used as matrix in the polymer composites. It is obtained from Araldite HY-951 Huntsman, Bangalore. Epoxy is a clear liquid with viscosity at $25^{\circ} \mathrm{C}$. Epoxies are used by the plastic industry in several ways. Hardener is used as reaction agent. It acts as catalyst. It is added to the resin in 10:1 proportion to get hardener. In the recent work Aradur HY-951 is used as hardener in the Epoxy LY556. It has a shelf pot life of 2 years when it is stored in a dry place in a temperature range of $18-25^{\circ}$ $\mathrm{C}$, while for achieving higher pot life; lid should be closed after using the material. Polyvinyl alcohol (PVA) was used as the mould releasing agent in composite fabrication. The mould cavity is coated with a thin layer of aqueous solution of PVA for the easy removal of the sheet from the mould and for a smooth surface finish. 
Table 1: List of raw materials used for micro-composites.

\begin{tabular}{|l|l|}
\hline Description & Raw Materials \\
\hline Matrix & Epoxy resin (LY-556) \\
\hline Hardener & Hardener (HY-951) \\
\hline Reinforcing agent & Coir Fiber \\
\hline Mould releasing agent & Polyvinyl alcohol (PVA) / Wax \\
\hline silicon & 200 mesh white powder \\
\hline Casting & Glass moulds \\
\hline
\end{tabular}

\section{Natural Silica / Micro Silica:}

Silica is a chemical compound consisting of one part silicon and two parts oxygen. Silica is one of the most complex and most abundant families of materials, existing both as several minerals and being produced synthetically. Notable examples include fused quartz, crystal, fumed silica, silica gel, and aero gels. Applications range from structural materials to microelectronics to components used in the food industry. Paints and Plastics, Polymer Compounds, Rubber, Sealants and Adhesives: Crystalline silica, in its finest flour form is used as reinforcing filler. Silica flour provides resistance against abrasive actions and chemical attack. Self-cleaning exterior wall coatings and heavy-duty offshore or marine paints are typical examples. The intrinsic properties of silica flour promote its use in plastics for encapsulating electronic components. An estimated 95\% of silicon dioxide produced is consumed in the construction industry, e.g. for the production of cement. Silica is used primarily in the production of glass for windows, drinking glasses, beverage bottles, and many other uses. The majority of optical fibers for telecommunication are also made from silica. It is a primary raw material for many ceramics such as earthenware, stoneware, and porcelain. Silicon dioxide is also used to produce elemental silicon. The process involves carbothermic reduction in an electric arc furnace. This makes it a very essential mineral in our dayto-day life.

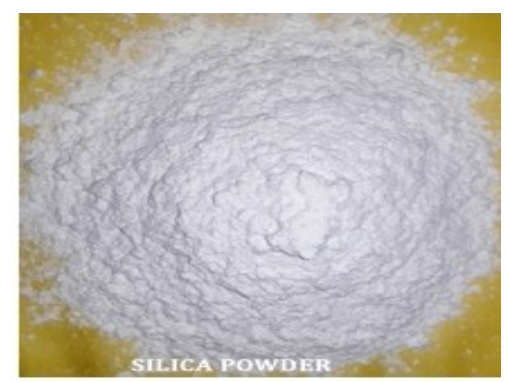

Fig. 1: Silica Grades 
Product Name high purity natural silica sand High quality Silica powder 200 mesh.

Applications Glass ,pottery \& paints.

Table 2: Chemical Composition

\begin{tabular}{|c|c|}
\hline Color & White \\
\hline SiO2 (\%) & 99.5 \\
\hline Al2O3 (\%) & 0.15 \\
\hline Fe2O3 (\%) & 0.041 \\
\hline CaO (\%) & 0.1 \\
\hline MgO (\%) & 0.05 \\
\hline
\end{tabular}

\section{Composite Manufacturing}

In general, the reinforcing and matrix materials are combined, compacted and processed to undergo a moulding process. After the moulding process, the part shape is essentially set, although it can deform under certain process conditions. For a thermo set polymeric matrix material, the melding event is a curing reaction that is initiated by the application of additional heat or chemical reactivity such as organic peroxide. For a thermoplastic polymeric matrix material, the melding event is solidification from the melted state. For a metal matrix material such as titanium foil, the melding event is a fusing at high pressure and a temperature near the melt point. For many moulding methods, it is convenient to refer to one mould piece as a "lower" mould and another mould piece as an "upper" mould. Lower and upper refer to the different faces of the molded panel, not the mould's configuration in space. In this convention, there is always a lower mould, and sometimes an upper mould. Part construction begins by applying materials to the lower mould. Lower mould and upper mould are more generalized descriptors than more common and specific terms such as male side, female side, a-side, b-side, tool side, bowl, hat, mandrel, etc. Continuous manufacturing processes use a different nomenclature

\section{Synthesis of Coir Fiber/Epoxy Composites}

In the present work glass moulds are used to prepare coir fiber reinforced with epoxy composites. A glass mould of $(130 \times 130 \times 0.4) \mathrm{mm}^{3}$ is used to prepare casting and specimen for tensile test, flexural tests and morphology. Moulds are prepared for different castings that are made from resin as per ASTM standards. The pre - calculated amount of Epoxy (resin) is mixed in a suitable beaker. Silicon filler is taken with stipulated quantity of resin based on the predetermined ratio and mixed thoroughly with mechanical shear mixing for about 1 hour at ambient temperature conditions. Then the mixer is carried out through a high intensity Ultrasonic for one and half hour with pulse mode (50s on / 25s off). External cooling system is employed to avoid temperature during the Ultrasonic process, by submerging the beaker containing the mixer in an ice and then a pre-calculated amount of hardener was mixed and stirred for 20 min before pouring into the mould bath.

Once the irradiation is completed, hardener is added to the modified epoxy in the ratio of 10:1 parts by weight. A glass mould with required dimensions is use for making sample as per the ASTM standards and it is coated with mould releasing agent enabling easy removal of the sample. In this technique coir fiber is wetted by a thin layer of an epoxy and epoxy suspension in a mould. Staking of coir fiber is arranged side by side all over the mould. Stacking of coir fiber is carefully arranged after pouring some amount of resin against the mould, to keep the poor impregnation at bay.

Left over quantity of mixture is poured over the coir fiber. Brush and roller are used to impregnate fiber. The closed mould is kept under the pressure for 24 hours at room temperature to 
ensure complete curing; the composite samples are post cured at $70^{\circ} \mathrm{C}$ for 1 hour in an oven and the test specimens of the required size is cut out from the sheet. The removed castings are cut into the samples in accordance with ASTM standards for further testing.

Direct processing technique has been used for the above fiber reinforced composites preparation. This procedure is applied for all the specimens.

Characterization encompasses mechanical (tensile, flexural tests), Chemical resistance test, Morphology (SEM test). In each case at least three samples are tested and the coefficient intervals (CI), standard error and \% change on mean values for the best samples are tabulated. The following different composites are prepared.

\section{Practical Work Specimen Photographs are listed}

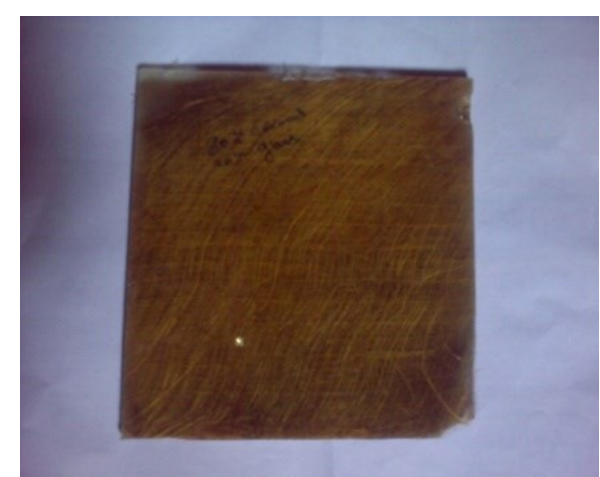

Fig. 2: Treated coir fiber Specimen 2

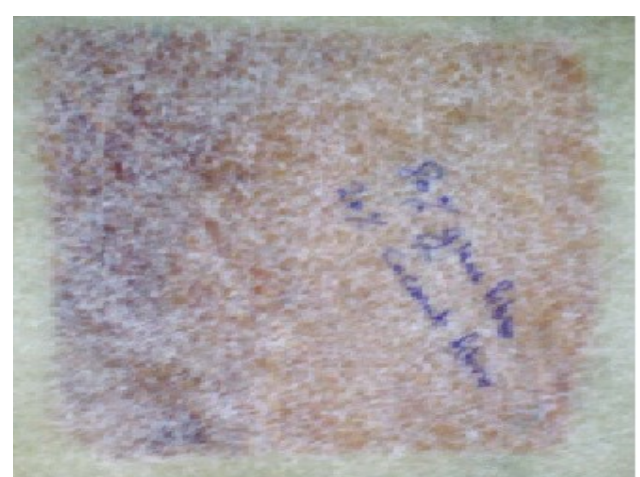

Fig. 3: Specimen 3 untreated fibers

\section{Flexural Load Measurements}

Flexural strength and modulus were tested using an Instron Universal testing machine with a crosshead speed of $2 \mathrm{~mm} / \mathrm{min}$. The three-point bending test system was used for all samples. In each case, six samples were tested and the average value tabulated. Authors used $50 \mathrm{KN}$ load cell used for testing. Furthermore the sample sizes $100 \times 20 \times 4 \mathrm{~mm}$ were cut in accordance with ASTM D 618.

\section{Tensile Load Measurements}

Tensile strength was studied using an Instron Universal testing machine supplied by Instron Corporation; a series-9 automated testing machine was used with a crosshead speed of $5 \mathrm{~mm} / \mathrm{min}$. Testing samples were prepared in dumb-bell shapes and these dimensions are $100 \times 20 \times 4 \mathrm{~mm} 3$ based on the ASTM D 638 standards. In each case, three samples were tested and the average value tabulated.

\section{Scanning Electron Microscopy Analysis (SEM)}

A JEOL JSM 840A JAPAN scanning electron microscope (SEM) was used to study the morphology of fractured surfaces of composite samples at uniform magnifications. The fractured surfaces were gold-coated initially subjecting it to SEM analysis. The scanning electron microscope for different cross-sections with uniform magnification (i.e.300x) for different specimens is done. 


\section{RESULTS AND DISCUSSIONS}

\section{Mechanical Tests}

\section{Flexural Test}

Table 3: Flexural properties of untreated coir fiber reinforced epoxy filled silicon hybrid composites.

\begin{tabular}{|c|c|c|}
\hline Name of the sample & $\begin{array}{c}\text { Flexural strength } \\
{\left[\mathrm{N} / \mathrm{mm}^{2}\right]}\end{array}$ & $\begin{array}{c}\text { Flexural modulus } \\
{\left[\mathrm{N} / \mathrm{mm}^{2}\right]}\end{array}$ \\
\hline Epoxy(94\%)+CoirFiber (2\%)+ Silicon (4\%)(S1) & 208.35 & 1156.73 \\
\hline Epoxy(94\%)+CoirFiber (4\%)+ Silicon (2\%)(S1) & 210.52 & 1263.25 \\
\hline Epoxy(95\%)+CoirFiber (5\%)+ Silicon (1\%)(S1) & 209.64 & 1162.12 \\
\hline
\end{tabular}

Table 4: Flexural properties of treated coir fiber reinforced epoxy filled silicon hybrid composite.

\begin{tabular}{|l|c|l|}
\hline Name of the sample & $\begin{array}{c}\text { Flexural strength } \\
{\left[\mathrm{N} / \mathrm{mm}^{2}\right]}\end{array}$ & $\begin{array}{c}\text { Flexural modulus } \\
{\left[\mathrm{N} / \mathrm{mm}^{2}\right]}\end{array}$ \\
\hline Epoxy(94\%)+CoirFiber(2\%)+Silicon(4\%) (S1) & 209.39 & 1263.55 \\
\hline Epoxy(94\%)+CoirFiber(4\%)+Silicon(2\%)(S2) & 212.12 & 1582.96 \\
\hline Epoxy(94\%)+CoirFiber(5\%)+Silicon(1\%)(S3) & 210.59 & 1459.21 \\
\hline
\end{tabular}

Flexural strength and Flexural modulus are tabulated at table 3 and table 4 . And the graphs are plotted for the specimens. It is shown in figure 4 and figure 5. Linearly increasing duo properties were observed up to $4 \% \mathrm{wt}$. of fiber i.e., specimen no. S2, and then a sudden fall were observed at $5 \%$ wt. of fiber, seen clearly in Figure 4 and 5 . We studied mechanical behavior of treated and untreated coir fiber-reinforced silicon filled with epoxy hybrid composites in which they have shown improved flexural strength and modulus at $4 \% \mathrm{wt}$. fiber due to the presence of silicon layers located at the interface of the fiber and the matrix. The filler layers may enhance the interfacial properties up to some concentrations. For untreated coir fiber reinforced epoxy filled with silicon composite, flexural strength and modulus are comparably decreased. It was observed that duo properties were increased up to $4 \%$ wt. fiber content and $2 \%$ silicon filler content, and then strength and modulus gradually decrease as fiber quantity increased to $5 \% \mathrm{wt}$. and $1 \%$ silicon. Optimal values were obtained at $4 \%$ wt. fiber content as shown in Table 4 . We observed flexural strength and modulus values are increased for treated coir fiber at $4 \% \mathrm{wt}$. and $2 \%$ silicon filler i.e., specimen 2 in system 2 compared with untreated coir fiber. 


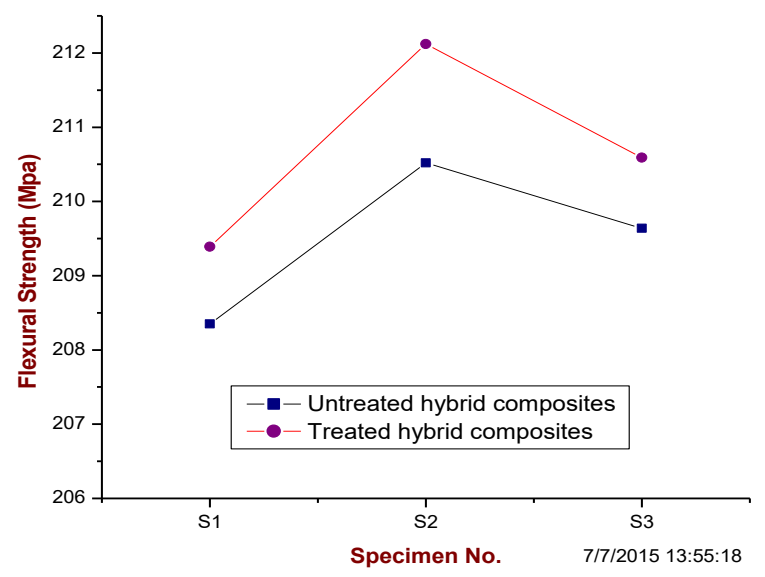

Fig.4: System $1 \& 2$ Flexural strength of untreated and treated coir fiber reinforced epoxy filled silicon hybrid composite.

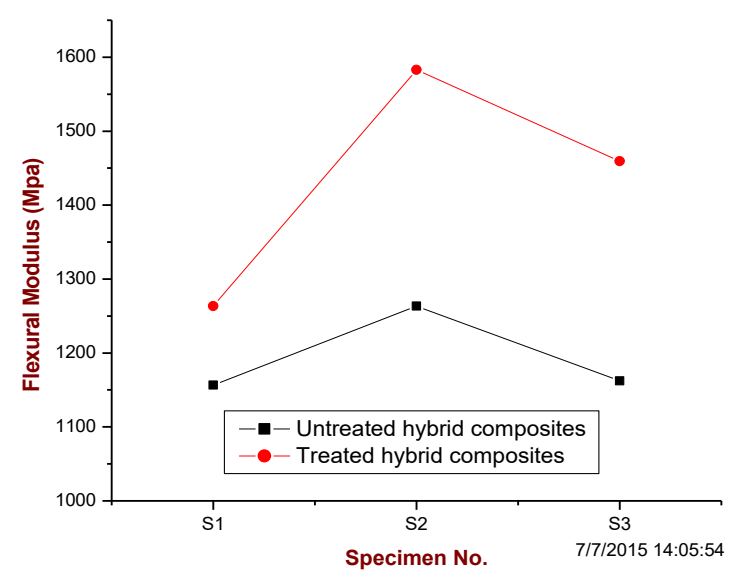

Fig. 5: System $1 \& 2$ Flexural modulus of untreated and treated coir fiber reinforced epoxy filled silicon hybrid composite.

\section{Tensile Test}

In our research work we have synthesized two different systems epoxy resin as Matrix along with the materials chosen for reinforcement are namely (a) Chemical Treated Coir fiber with silicon and (b) Untreated Coir fiber with silicon respectively. Table 5 shows the experimental measurements of tensile strength and modulus of untreated coir fiber with silicon contents. It was observed that tensile strength and modulus properties increase when fiber content is increased up to $4 \%$ wt. and decreases with further increase in fiber content. Tensile strength and modulus have been improved by 105.23 and maximum improvements at $4 \% \mathrm{wt}$. treated coir fiber content of silicon $2 \%$ (i.e., Specimen 2) compared with untreated coir fiber at $4 \% \mathrm{wt}$. \& silicon $2 \%$, respectively. 
Table 5: Tensile properties of untreated coir fiber reinforced epoxy filled silicon hybrid composites.

\begin{tabular}{|c|c|c|}
\hline Name of the sample Treated & $\begin{array}{c}\text { Tensile strength } \\
{\left[\mathbf{N} / \mathbf{m m}^{2}\right]}\end{array}$ & $\begin{array}{c}\text { Tensile modulus } \\
{\left[\mathbf{N} / \mathbf{m m}^{2}\right]}\end{array}$ \\
\hline $\begin{array}{l}\text { Epoxy }+ \text { Coir Fiber }+ \text { Silicon (S1) } \\
94 \% \quad 2 \% \quad 4 \%\end{array}$ & 99.89 & 1485.89 \\
\hline $\begin{array}{lll}\text { Epoxy } & \text { Coir Fiber }+ \text { Silicon }(\mathrm{S} 2) \\
94 \% & 4 \% & 2 \%\end{array}$ & 105.23 & 1792.77 \\
\hline $\begin{array}{l}\text { Epoxy }+ \text { Coir Fiber }+ \text { Silicon }(\mathrm{S} 3) \\
94 \% \quad 5 \%\end{array}$ & 104.44 & 1675.30 \\
\hline
\end{tabular}

Table 6: Tensile properties of treated coir fiber reinforced epoxy filled silicon hybrid composites.

\begin{tabular}{|c|c|c|}
\hline Name of the sample & $\begin{array}{c}\text { Tensile strength } \\
{\left[\mathbf{N} / \mathbf{m m}^{2}\right]}\end{array}$ & $\begin{array}{c}\text { Tensile modulus } \\
{\left[\mathbf{N} / \mathbf{m m}^{2}\right]}\end{array}$ \\
\hline $\begin{array}{ccc}\text { Epoxy + Coir Fiber + Silicon (S1) } & \text { C } \\
94 \% & 2 \% & 4 \% \\
\end{array}$ & 97.40 & 1295.30 \\
\hline $\begin{array}{ccc}\text { Epoxy + Coir Fiber + Silicon (S2) } & \text { C } \\
94 \% & 4 \% & 2 \% \\
\end{array}$ & 101.30 & 1590.54 \\
\hline $\begin{array}{ccc}\text { Epoxy + Coir Fiber + Silicon (S3) } \\
94 \% & 5 \% & 1 \% \\
\end{array}$ & 100.71 & 1519.40 \\
\hline
\end{tabular}

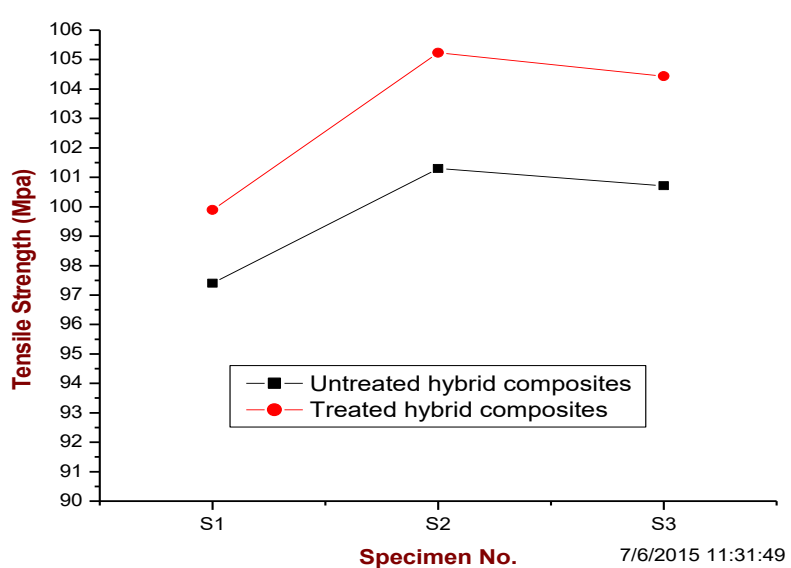

Fig. 6: Tensile strength of untreated and treated coir fiber reinforced epoxy filled silicon. 


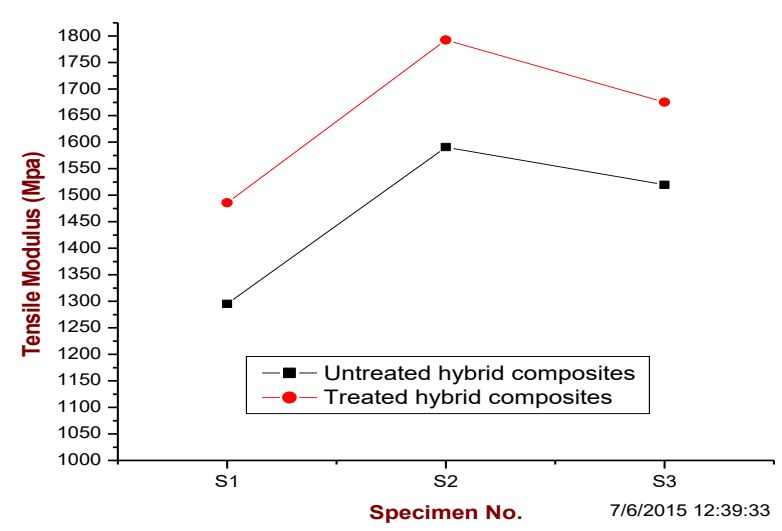

Fig. 7: Tensile modulus of untreated and treated coir fiber reinforced epoxy filled silicon.

From the graphs it is observed that system 2 specimen 2 showed highest tensile strength and Tensile modulus compared to system1.

Similarly for the second system, experimental measurements of tensile strength and modulus properties of treated coir fiber reinforced silicon filled with epoxy composites are shown in Table 6 . For the coir fiber-reinforced composite (4\% wt. fiber content) duo properties were $101.30 \mathrm{Mpa}$ and 105.23 Mpa, respectively. Duo properties are increased up to 4\% wt. fiber content, and then decreases as fiber quantity increased up to $5 \%$ wt. as shown in Figure 6 and 7 . Mittal studied a linear increase in tensile modulus observed with the filler volume fractions owing to partial exfoliation of the silicon up to $2 \%$ wt.

An interface $1 \mathrm{~mm}$ thick represents roughly $0.3 \%$ of the total volume of the polymer in micro particle-filled composites, where it can reach $30 \%$ of the total volume in the case of silicon filled composites. However, high surface area causes a strong tendency to agglomerate, which reduces the strength of composites by its stress concentration effect. Optimal loading of treated coir fiber and silicon in matrix is the key parameter to develop hybrid composites. Research revealed that true reduction in interfacial interactions lower the efficiency of the silicon in strengthening of epoxy.

\section{SEM Analysis on Fractured Surfaces:}

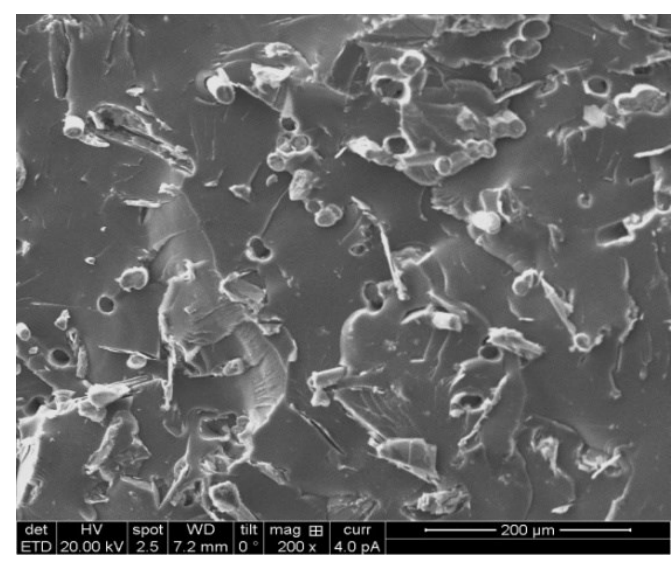

Fig. 8: SEM analysis on specimen S2 $4 \%$ wt.. of untreated fiber.

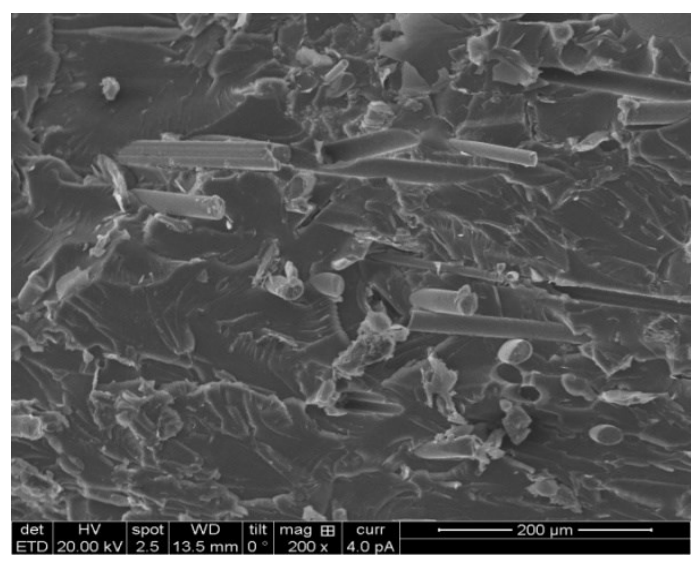

Fig. 9: SEM analysis on specimen S2 $4 \%$ wt.. of Treated fiber. 
Cross-sections of fractured surfaces of the hybrid composites (magnification size: 300X) of two systems namely untreated coir fiber reinforcement as a function of silicon filler and treated coir fiber reinforcement as a function of silicon filler are shown in Figure 8 and 9 respectively. As depicted in Figure 8, smooth fractured surfaces were observed on epoxy reinforced with coir fiber indicating a relatively brittle fracture. In Figure 9, the bright feature treated coir fiber of composite structures indicates a significant increase in cross-linking between fiber and matrix. It has observed that higher fractions of coir fiber and silicon resulting micro voids which act as stress concentration factors and facilitate shear yielding in the system, and therefore, reduces tensile and flexural strength in fractured cross-sections through SEM images.

\section{Chemical Resistance}

In each case, three samples are pre-weighed in a precision electrical balance and dipped in the respective chemical reagents for $24 \mathrm{hrs}$. Then they are removed immediately, washed with distilled water and dried by pressing them on both sides with a filter paper at room temperature as is the practice. The treated samples are then reweighed and \% loss / gain are determined using the following equation.

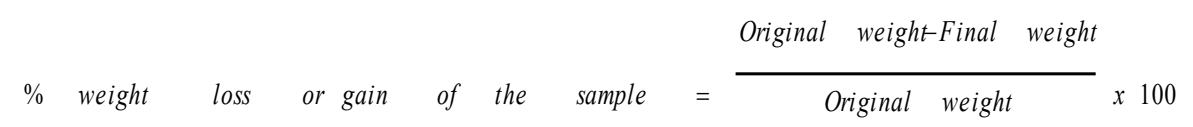

The \% weight gain $(+) /$ loss (-) values are evaluated after the samples are immersed in acids, alkalis, and solvents as presented in Table 7. When hybrid composites are subjected to solvents and acids, there is a weight gain. This may be due to the formation of gel instead of dissolution and also indicated existence of good bonding between the fiber and matrix, which promoted the close packing at molecular level. It is further observed from the Tables that the composites under the study are also resistant to distilled water. Sodium carbonate loses its weight, when samples are dipped in it and this is due to attack of sodium on the cross-linked epoxy resin. It is clearly evident that weight gain is observed for almost all the chemical reagents except sodium carbonate and Toluene. It is also observed from the Table 7 that untreated coir fiber hybrid composites also lost weight in sodium carbonate. The reason is attack of the carbonated hydrocarbons on the crosslinked epoxy fibre system. The positive values indicate that the composite materials are swollen with gel formation rather than dissolving in chemical reagents. It is further observed that composites are also resistant to water. This study epitomizes clearly that the coir fiber reinforced composites are substantially resistant to all chemicals except sodium carbonate. It is clearly indicates from the Table 7, treated coir fiber reinforced silicon filled composites are good resistance with all the chemicals except sodium carbonate and toluence. The two composites it is found out that treated coir fiber composites are good at attacking than untreated fiber. Therefore, observations suggest that these treated coir fiber reinforced silicon composites can best be used in aerospace, automobile, and marine applications for making water, fuel and chemical storage tanks. 
Table 7: Experimental values on effects of chemicals on weight of silicon filled epoxy matrix hybrid composites as a function of treated coir fiber at \% change in weight after dipping for $24 \mathrm{hr}$.

Name of the (Epoxy + Coir Fiber + Silicon $) \quad$ composite as a function of treated coir fiber

\begin{tabular}{lccl}
\cline { 2 - 4 } Chemical & 2 wt. $\%$ & 4 wt. $\%$ & 5 wt. \% \\
\cline { 2 - 4 }$(\mathrm{HCl})(10 \%)$ & +0.873 & +0.340 & +0.578 \\
$(\mathrm{CH}$ COOH $)(5 \%)$ & +0.240 & -0.955 & +0.186 \\
$(\mathrm{HNO} 3)(40 \%)$ & +1.678 & +1.566 & +1.818 \\
$(\mathrm{NaOH})(10 \%)$ & +1.265 & +0.875 & +0.579 \\
$\left(\mathrm{Na}_{2} \mathrm{CO}\right)(20 \%)$ & -0.210 & -0.177 & -0.155 \\
$\left(\mathrm{NH}_{4} \mathrm{OH}\right)(10 \%)$ & +0.767 & +0.404 & +0.731 \\
$\left.\mathrm{Benzene}_{\mathrm{T}}\right)$ & +10.426 & +7.575 & +22.721 \\
$\mathrm{CCl}_{4}$ & +7.086 & +8.282 & +7.936 \\
$\mathrm{H}_{2} \mathrm{O}$ & +2.145 & +3.208 & -14.451 \\
& +1.023 & +1.238 & +0.652
\end{tabular}

Table 8: Experimental values on effects of chemicals on weight of silicon filled epoxy matrix hybrid composites as a function of untreated coir fiber at \% change in weight after dipping for $24 \mathrm{hr}$.

Name of the (Epoxy + Coir Fiber + Silicon) composite as a function of untreated coir fiber

\begin{tabular}{|c|c|c|c|}
\hline Chemical & 2 wt. $\%$ & 4wt. \% & 5 wt. $\%$ \\
\hline$(\mathrm{HCl})(10 \%)$ & +0.543 & +0.485 & +0.653 \\
\hline$\left(\mathrm{CH}_{3} \mathrm{COOH}\right)(5 \%)$ & +1.340 & -1.643 & +1.346 \\
\hline$\left(\mathrm{HNO}_{3}\right)(40 \%)$ & +1.864 & +1.234 & +1.677 \\
\hline$(\mathrm{NaOH})(10 \%)$ & +1.567 & +0.577 & +0.444 \\
\hline$\left(\mathrm{Na}_{2} \mathrm{CO}_{3}\right)(20 \%)$ & -0.224 & -0.125 & 0.174 \\
\hline$\left(\mathrm{NH}_{4} \mathrm{OH}\right)(10 \%)$ & +0.865 & +0.655 & +0.555 \\
\hline Benzene & +10.226 & +7.862 & +22.421 \\
\hline Toluene & -8.564 & -7.045 & -6.758 \\
\hline $\mathrm{CCl}_{4}$ & +2.145 & +3.751 & -14.444 \\
\hline $\mathrm{H}_{2} \mathrm{O}$ & +1.009 & +1.254 & +0.678 \\
\hline
\end{tabular}




\section{CONCLUSION}

Reinforced coir fiber epoxy filled with silicon hybrid composites were synthesized with different concentrations of coir fiber / silicon dispersion through in situ polymerization. Flexural strength, flexural modulus, tensile strength and modulus were increased correspondingly up to $4 \%$ wt. for reinforced untreated coir fiber epoxy filled with silicon filler and similarly for $4 \% \mathrm{wt}$. for reinforced treated coir fiber epoxy filled with silicon filler respectively, and decreases with further addition of fiber contents. Thus it can be concluded that hybrid composites can be used for high strength, stiffness, and bending applications in aerospace, automobile, and marine and lightweight article applications. Overall studies indicated that the coir fiber reinforced hybrid composites at $4 \%$ wt. treated fiber and $2 \%$ wt. of silicon loading are promising candidates for structural applications where high strength and stiffness is indispensable. It was observed that duo properties were increased up to $4 \% \mathrm{wt}$. coir fiber content and $2 \%$ silicon filler content, and then strength and modulus gradually decrease as fiber quantity increased to $5 \% \mathrm{wt}$. and silicon to $1 \%$. Optimal values were obtained at $4 \%$ wt. fiber content. We observed flexural strength and modulus values are increased for treated coir fiber at $4 \%$ wt. and $2 \%$ silicon filler i.e., specimen 2 in system 2 compared with untreated coir fibers. The present study thus bears testimony to all of these findings. Hence the present study not only discloses that treated coir fiber overseen through the polymer with different surface treatment promotes the performance of composites, but that unique tailored properties are improved by changing the proportions of the coir fiber / silicon filler on the matrix.

\section{Acknowledgements}

It's my privilege to pay thanks to Department of Research and Development Polymer Science and Technology, at JNTU Hyderabad, Ranga Reddy and Geethanjali College of Engineering and Technology, Cheeryal(v), Keesara(M), Ranga Reddy(D). (T.S)-501301.

\section{References}

[1] M. Alexander and P. Dubois, Mater. Sci. Eng., 28, 1 (2000).

[2] H. Fischer, Mater. Sci. Eng. C, 23, 763 (2003).

[3] A. Akelah, P. Kelly, S. Qutubuddin, and A. Moet, Clays Clay Miner., 29, 169(1994).

[4] F. Hussain, M. Hojjati, M. Okamoto, and R. Gorga, J. Compos. Mater., 40, 1511 (2006).

[5] Y. Kojima, A. Usuki, M. Kawasumi, A. Okada, T. Kurau-chi, and O. Kamigaito,./. Polym. Sci. Part A: Polym. Chem., 31,983(1993).

[6] X. Kornmann, H. Lindberg, and L. Berglund, Polymer, 42, 1303 (2001).

[7] T. Agag and T. Takeichi, Polymer, 41, 7083 (2000).

[8] X. Kornmann, L. Berglund, J. Sterte, and E. Giannelis, Polym. Eng. Sci., 38, 1351 (1998).

[9] T. Agag and T. Takeichi, Polymer, 40, 6557 (1999).

[10] A. Akelah, A. Rehab, T. Agag, and M. Betiha, J. Appl. Polym. Sci., 103, 3739 (2007).

[11] A. Rehab, A. Akelah, T. Agag, and N. Shalaby, Polym. Compos., 28, 108 (2007).

[12] Y. Kojima, K. Fukumori, A. Usuki, A. Okada, and T. Kur-auchi, J. Mater. Sci. Lett., 12, 889 (1993).

[13] T. Lan and T. Pinnavaia, Chem. Mater., 6, 2216 (1994).

[14] D. Sagi-Mana, M. Narkis, A. Siegmann, R. Joseph, and H. Dodiuk, J. Appl. Polym. Sci., 69, 2229 (1998). 
[15] F. Cassis and R. Talbot, "Polyester and Vinyl Ester Resins," in Handbook of Composites, S. Peters, Ed., Chapman \& Hall Publishing, London, 34 (1998).

[16] T. Agag, A. Akelah, M. Abdelwahab, T. Takeichi, and H. Muto, J. Appl. Polym. Sci.,115, 2060 (2010).

[17] R. Brill and G. Palmese, J. Appl. Polym. Sci., 76, 1572 (2000).

[18] J. Chang and K. Park, Polym. Eng. Sci., 41, 2226 (2001).

[19] A. Anguly and A. Bhowmick, J. Mater. Sci., 44, 903 (2009).

[20] J. Cho and K.I. Sul, Polymer, 42, 727 (2001).

[21] S. Subramani, J. Lee, J. Kim, and I. Cheong, Compos. Sci. Technol., 67, 1561 (2007).

[22] G. Yi and F. Yan, Wear, 262, 121 (2007).

[23] A. Ranade, N. D'souza, and B. Gnade, Polymer, 43, 3759 (2002).

[24] T. Takeichi, K. Nakmura, T. Agag, and H. Muto, Design. Monom. Polym., 7, 727 (2004). 